\title{
GMR
}

\section{Agrobacterium-mediated transformation of tomato (Solanum lycopersicum L.) using the expansin 10 (CsEXP10) gene}

\author{
Y.D. Sun*, W.R. Luo*, S.Y. Sun and L. Ni \\ School of Horticulture and Landscape Architecture, \\ Henan Institute of Science and Technology, Xinxiang, Henan, China \\ *These authors contributed equally to this study. \\ Corresponding author: Y.D. Sun \\ E-mail: sunyd201@163.com \\ Genet. Mol. Res. 14 (4): 16215-16221 (2015) \\ Received June 28, 2015 \\ Accepted September 28, 2015 \\ Published December 8, 2015 \\ DOI http://dx.doi.org/10.4238/2015.December.8.11
}

\begin{abstract}
The cucumber expansin 10 (CsEXP10) gene was previously cloned from young cucumber fruits but its role has not been defined. To determine the role of this gene in plant growth and development, a CsEXP10 gene transformation system was established. The open reading frame of the gene was inserted behind the CaMV35S promoter of vector pCAMBIA1301, and the construct was introduced into tomato plants by Agrobacterium-mediated transformation. In total, 19 kanamycin-positive lines were produced and nine independent transgenic lines were identified by $\beta$-glucuronidase and polymerase chain reaction (PCR) analysis. Quantitative real-time PCR analysis showed that levels of the CsEXP10 transcript were higher in transgenic lines than in a non-transgenic line.
\end{abstract}

Key words: CsEXP10; GUS-staining assay; Regeneration; Tomato (Solanum lycopersicum L.); Transformation system 


\section{INTRODUCTION}

The expansin genes belong to a large gene superfamily and are found throughout the plant kingdom (Cosgrove, 1999; Li et al., 2002; Carey and Cosgrove, 2007). They encode highly conserved, extracellular proteins called expansins, which have roles in cell wall extension and relaxation during cell expansion ( $\mathrm{Li}$ et al., 2003). These proteins promote cell wall loosening by binding to the surface of cellulose microfibrils, thereby disrupting hydrogen bonds between matrix polysaccharides and cellulose microfibrils, and allowing the wall to extend (Rose and Bennett, 1999; Cosgrove, 2000; Li et al., 2003) in various aspects of plant growth and development such as morphogenesis, fruit ripening (Rose et al., 1997; Brummell et al., 1999), pollination, abscission, floral organ development (Lee et al., 2001; Choi et al., 2006), and root hair growth (Lin et al., 2011). However, the role of each expansin differs during growth and development. To date, four types of plant expansin proteins have been identified: $\alpha$-expansins, $\beta$-expansins, expansin-like A proteins, and expansin-like B proteins (Sampedro and Cosgrove, 2005).

The genes encoding these proteins are expressed in different tissues and their expression can be modulated by a range of stimuli. These properties indicate that regulation of cell wall extensibility might be partly controlled by differential regulation of expansin genes (Vogler et al., 2003). In cucumber, 10 -expansins have been identified: CsEXP1 and CsEXP2 were found in growing cucumber hypocotyls (Cosgrove and Durachko, 1994); CsEXP3-CsEXP9 cDNAs were identified from cucumber root tissues under a microgravity environment; and CsEXP10 was identified and cloned from young cucumber fruits by cDNA amplified fragment length polymorphism (cDNA-AFLP) analysis by this group (Sun et al., 2005). Although, CsEXP10 has been shown to be differentially expressed in root, stem, leaf, and young fruit of cucumbers (Sun et al., 2006), its role has not been defined.

In order to determine the role of the CSEXP10 gene in plant growth and development, tomato (Solanum lycopersicum L.) lines over-expressing CsEXP10 were generated by Agrobacterium-mediated transformation. In this study, an efficient method of Agrobacteriummediated transformation from cotyledons of tomato was established. The transgenic plants were confirmed by polymerase chain reaction (PCR) and $\beta$-glucuronidase (GUS) analysis, and CsEXP10 gene expression was determined.

\section{MATERIAL AND METHODS}

\section{Plant material}

The tomato plants (Solanum lycopersicum L.) used in this study were maintained in our laboratory. Tomato seeds were surface sterilized using $0.1 \% \mathrm{HgCl}_{2}$ for 8 min with constant swirling, followed by five rinses in sterile distilled water. Surface-sterilized seeds were germinated under sterile conditions on 1/2 MS medium (Murashige and Skoog, 1962), containing 3\% sucrose and solidified with $0.7 \%$ agar, at $\mathrm{pH} 5.8$, under a 16-h light/8-h dark regime. After 10 days, cotyledons were excised from the germinated seedlings and used as explants for transformation.

\section{Construction of the plant expression vector}

The open reading frame sequence of the CsEXP10 gene was inserted in the sense orientation behind the CaMV35S promoter of the vector pCAMBIA1301 (designated here as 
pCAMBIA1301-CsEXP10; Figure 1). This plasmid contains a GUS gene, which ensures that only plant-specific GUS expression is detected in transgenic plant tissues. After confirming the successful insertion of the gene sequence by enzyme digestion and sequencing, the pCAMBIA1301-CsEXP10 construct was introduced into the Agrobacterium tumefaciens strain GV3101 using a freeze-thaw method (Hofgen and Willmitzer, 1988).

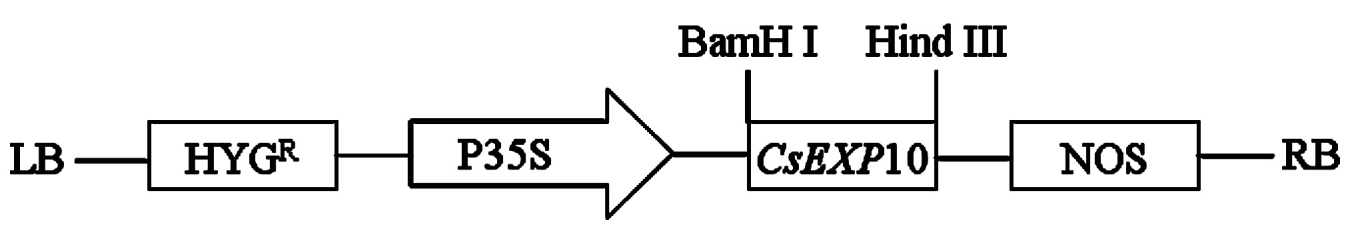

Figure 1. Structure of the plant expression vector pCAMBIA1301-CsEXP10 used for tomato transformation. $\mathrm{LB}=$ T-DNA left border; $\mathrm{HYG}^{\mathrm{R}}=$ hygromycin; $\mathrm{P} 35 \mathrm{~S}$ = promoter from cauliflower mosaic virus; $\mathrm{NOS}=$ nos terminator; $\mathrm{RB}=$ T-DNA right border.

\section{Tomato transformation}

Cotyledons from 10-day-old in vitro germinated seedlings were pre-cultured in MS medium containing $1.5 \mathrm{mg} / \mathrm{L}$ 6-benzyladenine (BA) and $0.2 \mathrm{mg} / \mathrm{L}$ indole acetic acid (IAA) for 2 days in the dark. They were then immersed in Agrobacterium suspension for 20 min under constant shaking. The cotyledons were then removed, blotted dry with a sterile filter paper to remove excess Agrobacterium suspension, and placed on petri dishes filled with MS medium containing $1.5 \mathrm{mg} / \mathrm{L}$ BA and $0.2 \mathrm{mg} / \mathrm{L}$ IAA under the same conditions as those mentioned above. After 2 days of culture, the cotyledons were transferred into a selection medium [MS medium $+1.5 \mathrm{mg} / \mathrm{L}$ BA + $0.2 \mathrm{mg} / \mathrm{L} \mathrm{IAA}+50 \mathrm{mg} / \mathrm{L}$ kanamycin (Kan) + $250 \mathrm{mg} / \mathrm{L}$ cefotaxime (Cef)] and incubated under a $12-\mathrm{h}$ light/12-h dark photoperiod at $25^{\circ} \mathrm{C}$. After 2 weeks, the first shoots formed. Shoots $(2-3 \mathrm{~cm}$ long) were excised from the explants and transferred to a rooting medium (MS medium $+0.2 \mathrm{mg} / \mathrm{L}$ IAA) without antibiotics to regenerate whole plants. Rooted plantlets were transplanted into pots containing sterile 1:1:1 (v/v/v) vermiculite/perlite/turf and grown under high relative humidity in an illuminated incubator for 2 weeks. The rooted plantlets were then transferred to a greenhouse.

\section{GUS-staining assay}

The leaves of transgenic plants were analyzed for GUS gene expression with X-glucuronide, as described by Jefferson et al. (1987). The GUS reaction mixture consisted of a solution containing sodium phosphate $(\mathrm{pH} 7.0)$, chloramphenicol, Triton X-100, methanol, and X-glucuronide. The samples were incubated in the solution for $48 \mathrm{~h}$ at $37^{\circ} \mathrm{C}$. The reaction was stopped by adding $70 \%$ $(\mathrm{v} / \mathrm{v})$ ethanol; leaf pigments and chlorophyll were removed by repeated ethanol treatment.

\section{DNA extraction and PCR analysis}

Genomic DNA was isolated from the leaves of transgenic and non-transgenic lines using a Plant Genomic DNA Extraction Kit (Sun Shine Bio, Nanjing, China). PCR amplification was performed using specific primers containing a partial sequence of the pCAMBIA1301-CsEXP10 vector: forward 5'-ATGGCTTCTTCTCTTTCTCTCC-3' and reverse 5'-TGTAAAACGACGG 
CCAGT-3'. PCR was performed using the following program: pre-denaturation step at $94^{\circ} \mathrm{C}$ for 3 $\mathrm{min}$; followed by 30 cycles of amplification $\left(94^{\circ} \mathrm{C}\right.$ for $30 \mathrm{~s}, 54^{\circ} \mathrm{C}$ for $30 \mathrm{~s}$, and $72^{\circ} \mathrm{C}$ for $1 \mathrm{~min}$ ), and finally $72^{\circ} \mathrm{C}$ for $10 \mathrm{~min}$. The PCR products were separated by electrophoresis on a $1 \%$ agarose gel.

\section{Analysis of gene expression}

Fresh leaf tissue was ground in liquid nitrogen and extracted with total RNA extractor (Sangon, Shanghai, China). First-strand cDNA was synthesized using a M-MuLV First Strand cDNA Synthesis Reagent Kit (Sangon), according to the manufacturer instructions. Expression analysis of CsEXP10 was carried out by quantitative real-time PCR analysis using the CsEXP10 primers as follows, forward 5'-CCGTAACTGGGGCCAAAATT-3' and reverse 5'-TCCGGTGAA TGTCTGACCAA-3', and the $\beta$-actin primers, forward 5'-CCACGAAACTACTTACAACTCCATC-3' and reverse 5'-GGGCTGTGATTTCCTTGCTC-3'. The PCR was performed using the following program: pre-denaturation at $95^{\circ} \mathrm{C}$ for $3 \mathrm{~min}$, followed by 40 cycles of amplification $\left(95^{\circ} \mathrm{C}\right.$ for $10 \mathrm{~s}$, $55^{\circ} \mathrm{C}$ for $30 \mathrm{~s}$, and $72^{\circ} \mathrm{C}$ for $20 \mathrm{~s}$ ), and finally $72^{\circ} \mathrm{C}$ for $3 \mathrm{~min}$. Determination of relative mRNA levels was performed using the $2^{-\Delta \Lambda C t}$ method (Livak and Schmittgen, 2001).

\section{RESULTS AND DISCUSSION}

\section{Identification of transgenic tomato lines}

Genetic transformation has become an established technology used to investigate the role of genes in plants. One of the most effective means of gene transformation in dicotyledonous plants is through the use of Agrobacterium. In many instances, however, the lack of an efficient regeneration system limits the use of gene transformation technologies in plants. In this study, we obtained 19 independent Kan-positive tomato lines after transformation and in vivo culture (Figure 2). Since the vector contained an expression cassette of the GUS gene, GUS activity was used to select the transgenic plants. Nine transgenic lines exhibited GUS activity (Figure 3). The presence of the CsEXP10 gene in the genomic DNA was confirmed by PCR analysis. All nine transgenic lines carried an exogenous CsEXP10 gene of the expected size (807 bp; Figure 4), demonstrating that this system can be successfully used for the transformation of tomato.

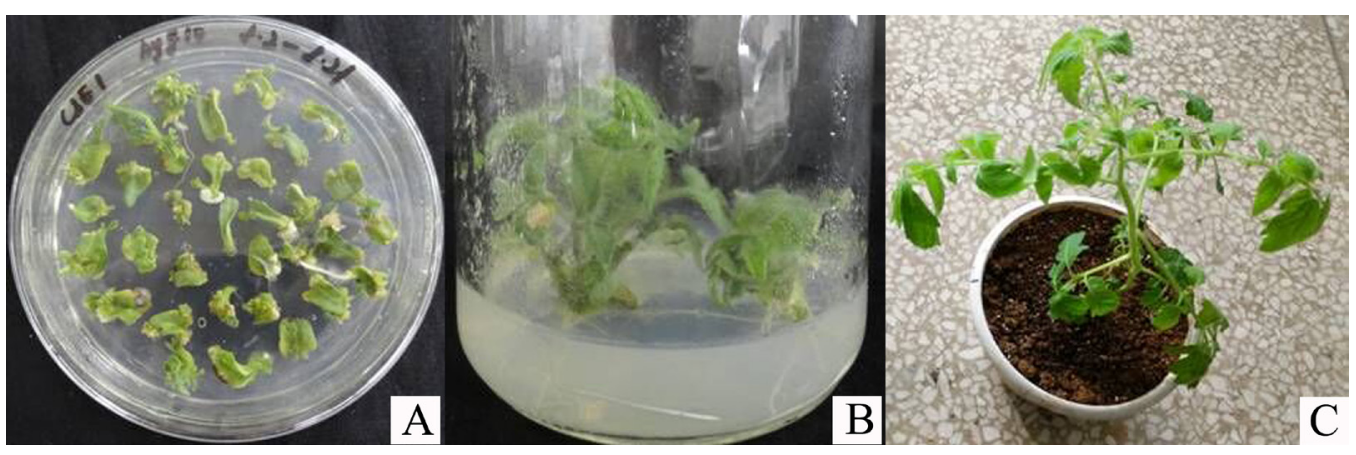

Figure 2. Regeneration of CsEXP10 transgenic tomato lines. A. Shoot formation; B. rooted plantlets; C. rooted plantlets growing in an illuminated incubator. 


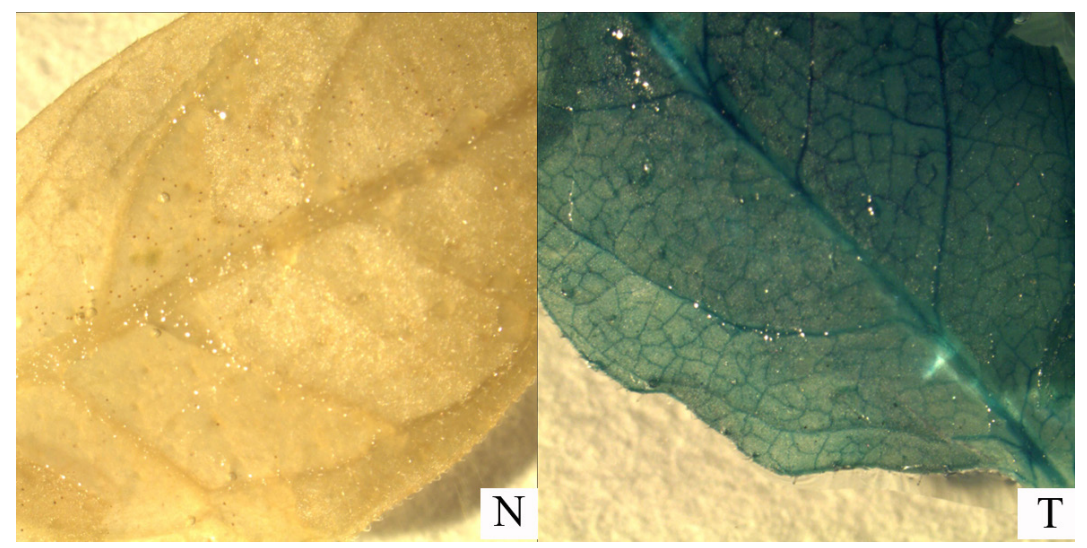

Figure 3. GUS-staining analysis of young tomato leaves. $\mathrm{N}=$ non-transgenic line (negative control); $\mathrm{T}$ = transgenic line.

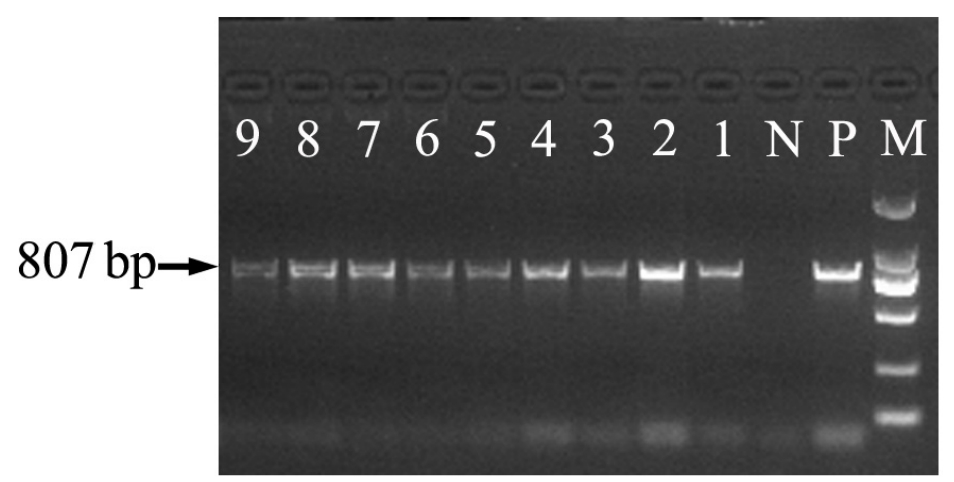

Figure 4. Identification of CsEXP10 transgenic tomato lines by PCR analysis. Lane $M=D L 2000^{\mathrm{TM}} \mathrm{DNA}$ marker; lane $P=$ plasmid DNA (pCAMBIA1301-CsEXP10) (positive control); lane $N=$ non-transgenic line (negative control); lanes $1-9=$ transgenic lines.

\section{Analysis of CsEXP10 gene expression}

Expression of the CSEXP10 gene was analyzed in the leaves of three randomly selected transgenic lines. Results from quantitative real-time PCR analysis indicated that the CsEXP10 gene was expressed in the transgenic tomato lines, which further confirmed that we had established a successful transformation system. Transcript levels were 2.05-, 3.24-, and 10.17-fold higher than those in the non-transgenic line (Figure 5). Hence, the transgenic lines tested showed increased transcript expression, among which line T2 showed the highest level of expression.

In our study, the open reading frame of the cucumber expansin gene CsEXP10 was used to create transgenic tomato lines, and an efficient method of Agrobacterium-mediated transformation from cotyledons of tomato was established. These transgenic lines had increased levels of the CsEXP10 gene transcript compared to the non-transgenic line. 


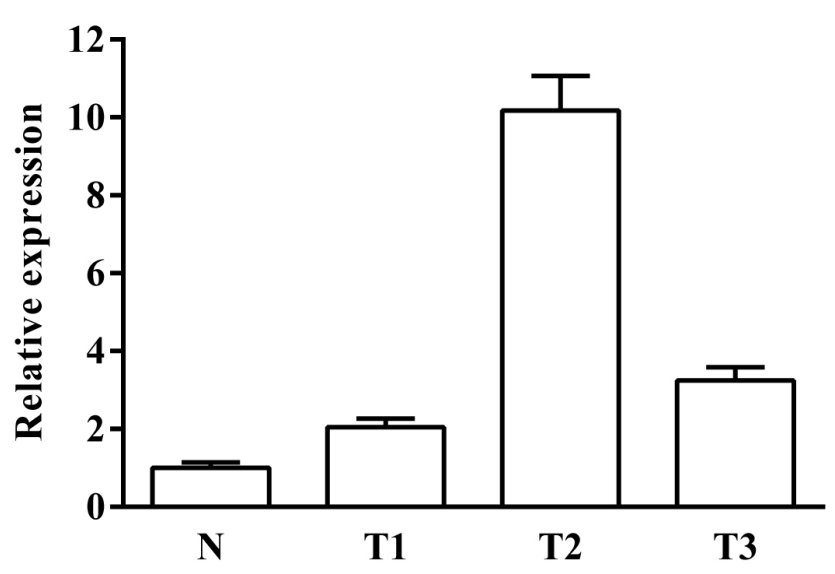

Figure 5. Expression of CsEXP10 gene in randomly selected transgenic tomato lines. $\mathrm{N}$ : non-transgenic line (negative control); T1, T2, T3: transgenic lines.

\section{Conflicts of interest}

The authors declare no conflict of interest.

\section{ACKNOWLEDGMENTS}

Research supported by the National Natural Science Foundation of China (\#U1204322 and \#3140860), the Henan Province Young Teacher Plan (\#2012GGJS-141) and the Science and Technology Develop Project of Xinxiang City (\#15NY06).

\section{REFERENCES}

Brummell DA, Harpster MH, Civello PM, Palys JM, et al. (1999). Modification of expansin protein abundance in tomato fruit alters softening and cell wall polymer metabolism during ripening. Plant Cell 11: 2203-2216.

Carey RE and Cosgrove DJ (2007). Portrait of the expansin superfamily in Physcomitrella patens: comparisons with angiosperm expansins. Ann. Bot. 99: 1131-1141.

Choi D, Cho HT and Lee Y (2006). Expansins: expanding importance in plant growth and development. Physiol. Plant. 126: 511-518.

Cosgrove DJ (1999). Enzymes and other agents that enhance cell wall extensibility. Annu. Rev. Plant Physiol. Plant Mol. Biol. 50: $391-417$.

Cosgrove DJ (2000). Loosening of plant cell walls by expansins. Nature 407: 321-326.

Cosgrove DJ and Durachko DM (1994). Autolysis and extension of isolated walls from growing cucumber hypocotyls. J. Exp. Bot. 45: 1711-1719.

Hofgen R and Willmitzer L (1988). Storage of competent cells for Agrobacterium transformation. Nucleic Acids Res. 16 : 9877. Jefferson RA, Kavanagh TA and Bevan MW (1987). GUS fusions: beta-glucuronidase as a sensitive and versatile gene fusion marker in higher plants. EMBO J. 6: 3901-3907.

Lee Y, Choi D and Kende H (2001). Expansins: ever-expanding numbers and functions. Curr. Opin. Plant Biol. 4: $527-532$.

Li Y, Darley CP, Ongaro V, Fleming A, et al. (2002). Plant expansins are a complex multigene family with an ancient evolutionary origin. Plant Physiol. 128: 854-864.

Li Y, Jones L and McQueen-Mason SJ (2003). Expansins and cell growth. Curr. Opin. Plant Biol. 6: 603-610.

Lin C, Choi HS and Cho HT (2011). Root hair specific EXPANSIN A7 is required for root hair elongation in Arabidopsis. Mol. Cells 31: 393-397. 
Livak KJ and Schmittgen TD (2001). Analysis of relative gene expression data using real-time quantitative PCR and the $2^{-\Delta \Delta C t}$ method. Methods 25: 402-408.

Murashige T and Skoog F (1962). A revised medium for rapid growth and bioassays with tobacco tissue cultures. Physiol. Plant. 15: 473-497.

Rose JK and Bennett AB (1999). Cooperative disassembly of the cellulose xyloglucan network of plant cell walls: parallels between cell expansion and fruit ripening. Trends Plant Sci. 4: 176-183.

Rose JK, Lee HH and Bennett AB (1997). Expression of a divergent expansin gene is fruit-specific and ripening-regulated. Proc. Natl. Acad. Sci. U. S. A. 94: 5955-5960.

Sampedro J and Cosgrove DJ (2005). The expansin superfamily. Genome Biol. 6: 242-253.

Sun YD, Zhang XG, Hou RX Guo SY, et al. (2005). Identification of expanding-related genes from young fruit of cucumber after pollination. J. Plant Physiol. Mol. Biol. 31: 403-408.

Sun YD, Zhang XG, Du XB, Su CG, et al. (2006). Cloning and expression of cucumber CsEXP10 gene. J. Plant Physiol. Mol. Biol. 32: 375-380.

Vogler H, Caderas D, Mandel T and Kuhlemeier C (2003). Domains of expansin gene expression define growth regions in the shoot apex of tomato. Plant Mol. Biol. 53: 267-272. 